\title{
Investigation of Mechanical Behavior for a Selected Rubber- Modified Epoxy Adhesive
}

\begin{abstract}
E. S. Khalaf*, S. M. Hassanein ${ }^{* *}$, M. K. Hadhoud ${ }^{* *}$
Abstract: Epoxy resin based on diglycidyl ether of bisphenol A and varying content of hydroxyl terminated polybutadiene (HTPB) were cured using a polyamide curing agent. The ultimate aim of the study was to modify the epoxy matrix by liquid rubber so as to improve its toughness. Tensile, flexural, and impact properties were evaluated. The morphological evolution of the toughened networks was examined by scanning electron microscope, and the observations were used effectively to explain the obtained impact properties.
\end{abstract}

Keywords: Epoxy resin, Modifiers, Mechanical properties, Adhesives, Morphology.

\section{Introduction}

Epoxy resins (ERs) are characterized by outstanding performances such as toughness, rigidity, high temperature performance, chemical resistance, adhesive properties, formulation latitude, and reactivity with a wide variety of chemical curing agents [1]. The resin can form a highly cross-linked network structure having relatively high stiffness and glass transition temperature (Tg) with high chemical resistance. Elastomeric modification is one of the most frequently used and widely accepted methods for improving toughness and other properties of epoxy networks. Hydroxyl terminated internally epoxidized polybutadiene rubber has been used as a modifier for epoxy matrix in a number of studies [2-4]. Barcia et al. [5] employed HTPB as a surface modifier in carbon fiber (CF) reinforced epoxy matrix composites. The surfaces of carbon fibers (CFs) were grafted with HTPB, and this formed a flexible interface between CF and epoxy matrix, which ultimately improved the mechanical behavior of the system. Ozturk et al. [6] employed modified HTPB rubbers to improve thermal and mechanical properties and ultimately to toughen an epoxy thermoset matrix.

The objective of the present study is to investigate the mechanical and fracture behavior of epoxy resin modified with hydroxyl terminated polybutadiene (HTPB) and thus to characterize the morphology and toughening mechanism. The obvious characteristic of the elastomer is its immiscible nature with the epoxy resin and hence in a phase separated state from the major epoxy matrix throughout the cure reaction. In the literature there are not many works on the structure-property relationship of epoxy-HTPB system. The importance of the study is the use of a polyamide as a curing agent. Based on the mechanical properties and morphological analysis, attempts have been made, to analyze toughening mechanisms prevailing in the phase separated matrix. Analysis of the structure-property relationship of epoxy-polyamide-HTPB system is a new endeavor to the best of our knowledge.

\footnotetext{
*Egyptian Armed Forces, iyads2000@yahoo.com

** Egyptian Armed Forces
} 


\section{Experimental}

\subsection{Materials}

The epoxy resin used was liquid diglycidyl ether of bisphenol A (DGEBA) (under the trade name, EPON 828) with a number average-molecular weight of 380 and an epoxide equivalent of 180-195 g/equiv produced by Hexion chemical co. A polyamide (under the trade name, VERSAMID 125) with an amine value of about $350 \mathrm{mgKOH} / \mathrm{g}$ was used as curative. The employed liquid hydroxyl terminated polybutadiene HTPB(USA origin), presents an (Mn) of 3000 and a hydroxyl number of $0.8 \mathrm{~g} / \mathrm{mg}$.equiv. See Fig. 1.

\subsection{Curing procedure}

The Epoxy resin (ER) was modified with different amount of HTPB. All network polymers were prepared from mixtures of the (ER) and the hardener, VERSAMID 125 (see Table 1 for the formulations). ER/HTPB samples were prepared as follows: a proper amount of EPON 828 was first degassed for $60 \mathrm{~min}$ in a vacuum oven at $80{ }^{\circ} \mathrm{C}$. The rubber (HTPB) was also degassed separately under the same conditions. Both components were mixed and then the curing agent was added. The mixtures were gently stirred for about $5 \mathrm{~min}$ to ensure proper dispersion of the hardener, then degassed for $5 \mathrm{~min}$ and finally poured into appropriated molds for mechanical testing. The cure was performed at $100^{\circ} \mathrm{C}$ for $120 \mathrm{~min}$.

Table 1 Formulations of pure ER and those rubber-modified epoxy systems

\begin{tabular}{|c|c|c|c|}
\hline \hline Materials code & ER $(\mathrm{g})$ & Versamid 125(g) & HTPB $(\mathrm{g})$ \\
\hline \hline & & & \\
\hline P0 & 100 & 54 & 0 \\
\hline P1 & 100 & 54 & 0.75 \\
\hline P2 & 100 & 54 & 1.5 \\
\hline P3 & 100 & 54 & 2.5 \\
\hline P4 & 100 & 54 & 5 \\
\hline P5 & 100 & 54 & 10 \\
\hline P6 & 100 & 54 & 15 \\
\hline P7 & 100 & 54 & 20 \\
\hline P8 & 100 & 54 & 25 \\
\hline \hline
\end{tabular}

\subsection{Characterization}

\subsubsection{Morphology analysis}

In this examination the grain size of the incorporated elastomeric particles and phase separation in the epoxy matrix were examined using a scanning electron microscope (SEM) type REMMA-202 equipped with X-ray microanalysis capability. Accelerating voltage is up to $40 \mathrm{KV}$, resolution can attain about $70 \mathrm{~A}$ 。 and magnification ranges $(10-400000) \mathrm{X}$ to examine the fracture surfaces of toughened epoxy matrices.

\subsubsection{Mechanical testing}

Stress-strain relations and modulus of elasticity were measured experimentally for each of the prepared formulations. The Zwick1487 universal test machine was used for carrying out tensile tests, at a crosshead speed of $5.08 \mathrm{~cm} / \mathrm{min}$. The tensile test was carried out for at least 
five samples for each prepared formulation and the mean value of the obtained results was recorded. Impact strength is defined as toughness or the ability of the material to withstand a sharp blow, such as that from a hammer. The standard Charpy notch impact test is carried out to determine the impact strength. The impact test was carried out at room temperature and the result was reported in $\left(\mathrm{kJ} / \mathrm{m}^{2}\right)$. The values were taken from an average of at least ten specimens.

Flexural tests were performed with rectangular samples according to ASTM D-790 using the tensile test machine model LLOYD LRX5K fitted with a three-point bending fixture at a crosshead speed of $0.5 \mathrm{~mm} / \mathrm{s}$. The dimensions of the samples were $3.2 \times 12.7 \times 125 \mathrm{~mm}$ and the span to thickness ratio was set at $\mathrm{L} / \mathrm{D}=25$ in all cases. The results are expressed in Mega Pascal (MPa), which is the average of the results from five samples. The flexural modulus was also determined.

\section{Results and Discussion}

\subsection{Tensile strength and related properties}

Stress-strain behaviors of the modified epoxies are shown in Fig. 2a-2b. From literature, the neat resin system exhibits a brittle tensile behavior characterized by a Young's modulus value of about $9820\left(\mathrm{kgf} / \mathrm{cm}^{2}\right)$. Addition of HTPB decreases Young's modulus showing ductile nature of modified systems. Generally, when a rubber modifier is added to a thermoset resin, its elastomeric character authorizes a significant decrease in Young's modulus. This was noted when a carboxyl terminated butadiene acrylonitryle $(\mathrm{CTBN})$ copolymer is used as a modifier, which was initially partially miscible with the resin, and was employed during the toughening study of epoxy resin by the authors [7]. Whereas, in this work, the modification by $(10 \mathrm{~g})$ HTPB resulted in a modulus of $9555\left(\mathrm{kgf} / \mathrm{cm}^{2}\right)$ as shown in Fig. 2c. This slight reduction may be attributed to the lowering in cross-linking density of the epoxy network as the modifier occupies the reaction centers during modification. The various tensile properties for different loadings of the rubber are formulated in Table 2. The decrease in tensile strength with rubber content can be related to stiffness of the modified network. The rubber addition decreases stiffness of the network epoxy probably due to lowering in cross-linking density. Since HTPB is less compatible with the resin, the volume fraction of the dispersed rubber phase becomes more significant that reduces the interaction in the epoxy matrix. The volume fraction of rubber increases with the increase in the addition of the elastomer. The tensile properties were gradually increased and the optimum conditions were achieved at $(2.5 \mathrm{~g})$ of (HTPB) loading and excessive addition will decrease the tensile values.

\subsection{Impact resistance}

The results obtained for impact resistance of neat epoxy and resin samples containing different amounts of the rubber are depicted in Fig. 3. All modified networks show higher impact resistance than neat resin. In this study, the impact resistance results together with the other mechanical properties mentioned before came to declare and insist on the new innovation that the polyamide and specifically Versamid hardener is so compatible with the (DGEBA), the reason which proves that toughness enhancement is not limited with inclusion of up to 10phr rubber but instead there is a flexible range[4] and [8]. 
Table 2 Tensile properties at room temperature with different loadings of rubber cured at $100 \mathrm{C}$

\begin{tabular}{|c|c|c|c|}
\hline \hline Materials code & $\begin{array}{c}\text { Tensile Stress } \\
\left(\mathrm{kgf} / \mathrm{cm}^{2}\right)\end{array}$ & $\begin{array}{c}\text { Tensile Strain } \\
(\%)\end{array}$ & $\begin{array}{c}\text { Young's modulus } \\
\left(\mathrm{kgf} / \mathrm{cm}^{2}\right)\end{array}$ \\
\hline \hline P0 & 364.81 & 3.99 & 9819.95 \\
\hline P1 & 429.89 & 4.02 & 10236.46 \\
\hline P2 & 444.44 & 4.44 & 12231.83 \\
\hline P3 & 608.57 & 6.46 & 10210.66 \\
\hline P4 & 540.37 & 5.72 & 10041.51 \\
\hline P5 & 450.94 & 5.13 & 9554.67 \\
\hline P6 & 410.96 & 4.97 & 8967.06 \\
\hline P7 & 391.26 & 4.73 & - \\
\hline P8 & 362.16 & 5.03 & - \\
\hline
\end{tabular}

\subsection{Flexural properties}

Figure 4 depicts the obtained flexural properties of neat and rubber-modified resin samples. The flexural strength of the modified samples increases till the limiting content and then decreases again. A very small amount of rubber may get incorporated into the epoxy matrix, thereby flexibilizes the thermoset network. The rubber that is incorporated into the resin matrix is responsible for the reduction in flexural strength of the modified samples. Previous works on rubber-modified epoxies support this observation [5], [9], [10], [11] and [12].

\subsection{Morphology and toughening behavior}

The obtained SEM photograph of a (10g) rubber-modified epoxy, Fig. 5a, clearly demonstrates the expected phase separation which is responsible for energy dissipation process which ultimately improves the fracture toughness of the modified epoxies. Detailed microscopic examination of the stress-whitening region proved presence of small closely spaced holes. The presence of such holes may be interpreted by the dilatational deformation of the particles and the matrix that nucleates local shear yielding of the epoxy matrix causing a significant crack tip deformation [13] and [14].

Figure $5 \mathrm{~b}$ shows relative smoothness of the fractured surface, irrespective of the presence of some shear deformation spots, indicates that no significant plastic deformation had occurred. The morphological development during cure can be correlated with the impact behavior. The brittle fracture of the network accounts for its poor impact strength, as there is no energy dissipation mechanism operating here. Figures $5 \mathrm{c}$, 5d (representing $2.5 \mathrm{~g}$ and $15 \mathrm{~g}$ rubbermodified epoxies respectively), clearly show two distinct phases - a continuous epoxy matrix and the dispersed rubber phase. This heterogeneous morphology resulted opacity in samples. The holes developed in the SEM micrographs are due to the extracted particles from the surface of the samples after treatment with toluene for $12 \mathrm{~h}$. The inter-particle distance of the rubber domains is also estimated and found to increase with higher inclusion of rubber demonstrating lesser interaction of rubber with the epoxy matrix. The increase in domain size with the incorporation of rubber is attributed to the coalescence of the dispersed rubber particles, which depends on viscosity and elasticity ratio. This becomes more prominent in higher weight content of the dispersed rubber phase. In epoxies with $(2.5 \mathrm{~g})$ and $(15 \mathrm{~g})$ of rubber incorporation, as shown in Figs. $5 \mathrm{c}, 5 \mathrm{~d}$, the particles are uniformly distributed 
throughout the matrix with a narrow particle size distribution. This unimodal distribution of smaller particles is responsible for lower crack growth in these specimens which is indicated by the presence of relatively large number of deformation lines. Also, the fracture surfaces, unlike neat epoxy, are not very smooth, indicative of a ductile manner of fracture. According to Yee and Pearson [15], the size of stress-whitened zone or the amount of deformation lines is proportional to the increase in toughness of the material. Also, less brightness of the interfacial layer around the rubber domains in lower modified epoxies compared to higher modified samples is indicative of the interaction between the particles and epoxy matrix [6]. The micrographs show stress-whitened zone of broken rubber particles. According to Lee et al. [16] and Bascom and Hunston [17], the stress-whitening is due to the scattering of visible light from the layers of the scattering center which are voids developed in the matrix due to cavitations of rubber particles. This has been explained by researchers as one of the most important energy dissipation mechanisms operating in rubber-modified epoxies.

\section{Conclusion}

Functionally terminated polybutadiene liquid rubber has been incorporated into the epoxy resin matrix that undergoes curing with a polyamide hardener. Inclusions of rubber, as observed from mechanical testing and with further confirmation by morphology analysis, caused enhancement in toughness of the epoxy network. This will be attributed to the reduction in concentration of reacting species and viscosity effect on the addition of rubber. Addition of rubber causes lowering in cross-linking density of epoxy matrix during the cure polymerization reaction. The mechanical performance of neat epoxy was changed with the inclusion of varying weight percentage of HTPB, which was explained by the evolution of morphological changes during cure in these systems. The elastomeric nature of the rubber caused reduction in tensile strength, but toughness values increased. Some amount of added rubber goes into the epoxy matrix and flexibilizes the brittle thermoset matrix. This effect is responsible for the deformation under shear of the matrix, and thus for the prevailing toughening effect. The flexural properties were found to decrease by the inclusion of rubber. The size of elastomer domains increased with the inclusion of greater weight percentage of rubber. The poor performances of mechanical properties of modified epoxies containing more than $(2.5 \mathrm{~g})$ of rubber are considered due to larger particle size. In that system, a toughening effect is observed as indicated by the best impact performance associated to improved flexural properties, because of the presence of rubber particles homogeneously dispersed inside the epoxy matrix.

To summarize, to achieve good mechanical properties and impact resistance, the polybutadiene particles must be well adhered to the epoxy matrix. This may be achieved by pre-reacting the epoxy resin with functionalized polybutadiene, thus forming a block copolymer. The different procedure to prepare this block copolymer exerts strong influence on the morphology and on the mechanical behaviour.

\section{References}

[1] H. Lee and K. Neville (1st ed), 'Epoxy resins' in EPST vol. 6, The Epoxylite Corporation (1967) p. 209-271.

[2] P. Bussi and H. Ishida, J Appl Polym Sci 53 (1994), p. 441.

[3] P. Bussi and H. Ishida, J Appl Polym Sci 35 (1994), p. 956.

[4] P.B. Latha, K. Adhinarayanan and R. Ramaswamy, Int J Adhes Adhes 14 (1994), p. 57. 
[5] F.L. Barcia, B.G. Soares, M. Gorelova and J.A. Cid, J Appl Polym Sci 74 (1999), p. 1424.

[6] A. Ozturk, C. Kaynak and T. Tincer, Eur Polym J 37 (2001), p. 2353.

[7] R. Thomas, J. Abraham, P.S. Thomas and S. Thomas, J Poly Sci Part B Polym Phys 42 (2004), p. 2531.

[8] D. Ratna, A.K. Banthia and P.C. Deb, J. Appl Polym Sci 80 (2001), p. 1792.

[9] F.L. Barcia, T.P. Amaral and B.G. Soares, Polymer 44 (2003), p. 5811.

[10] H. Harrani, S. Fellahi and M. Baker, J Appl Polym Sci 71 (1999), p. 29.

[11] I. Takao, Y. Naoto and M. Tomoi, Eur Polym J 28 (1992), p. 573.

[12] S. Manternal, J.P. Pascault and H. Sautereau In: C.K. Riew, Editor, Rubber toughened plastics, Advances in chemistry series vol. 222, American Chemical Society, Washington, DC (1989), p. 193.

[13] W.D. Bascom and D.L. Hunston In: K.W. Allex, Editor, Adhesives vol. 6, Applied Science Publishers, London (1980).

[14] D.L. Hunston and W.D. Bascom In: C.K. Riew and J.K. Gillham, Editors, Rubber modified thermoset resins, Advances in chemistry series no. 208, American Chemical Society (1984), pp. 83-99.

[15] A.F. Yee and R.A. Pearson, J Mater Sci 21 (1986), p. 2462.

[16] W.H. Lee, K.A. Hodd and W.W. Hodd In: C.K. Riew, Editor, Rubber toughened plastics, Advances in chemistry series vol. 222, American Chemical Society, Washington, DC (1989), p. 263.

[17] W.D. Bascom and D.L. Hunston In: C.K. Riew, Editor, Rubber toughened plastics, Advances in chemistry series vol. 222, American Chemical Society, Washington, DC (1989), p. 135. 
a- Epoxy resin (Epon-828)

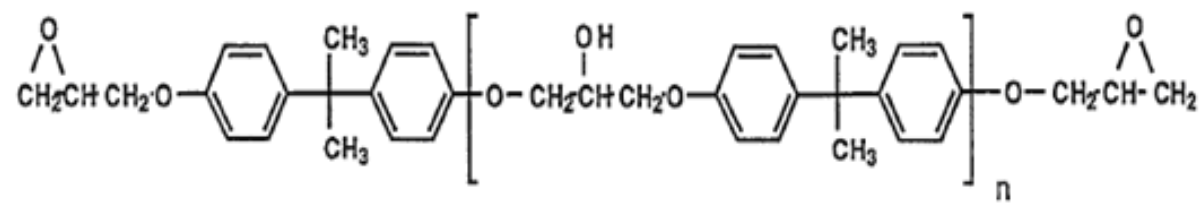

b-Versamid 125 (complex reaction product of acid dimer and diethylenetriamine)

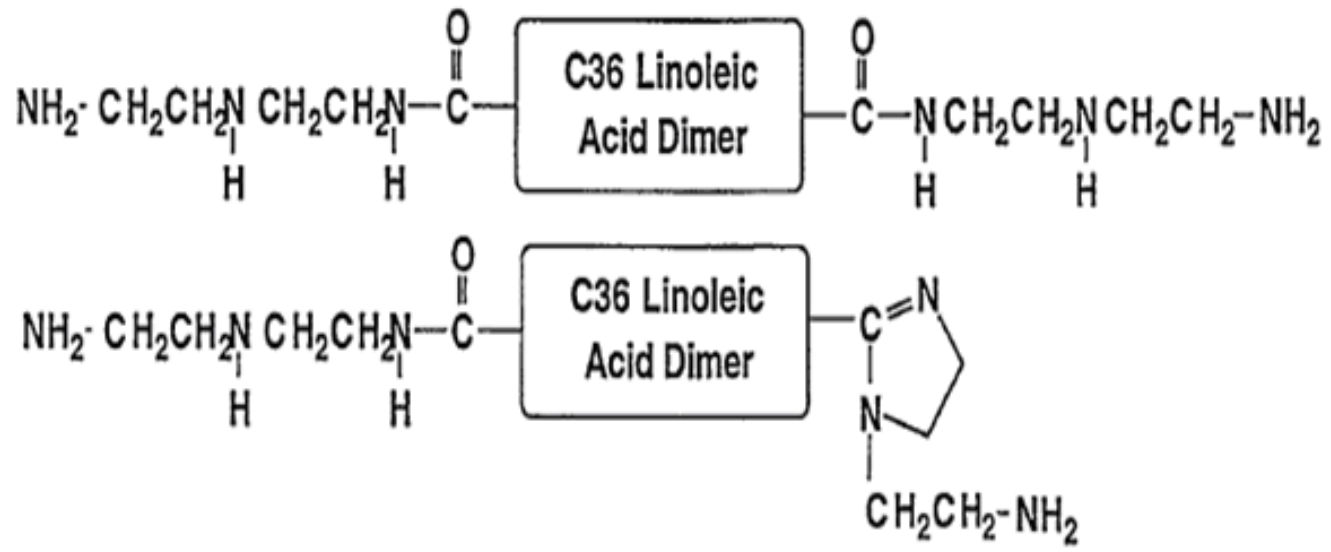

c- HTPB

$\mathrm{HO}-(\mathrm{CH} 2-\mathrm{CH}=\mathrm{CH}-\mathrm{CH} 2) \mathrm{n}-\mathrm{OH}$

C36 Linoleic

Acid Dimer $=$ A bulky, oil-compatible, C36 carbon group

Fig. 1 Structure of compounds. 


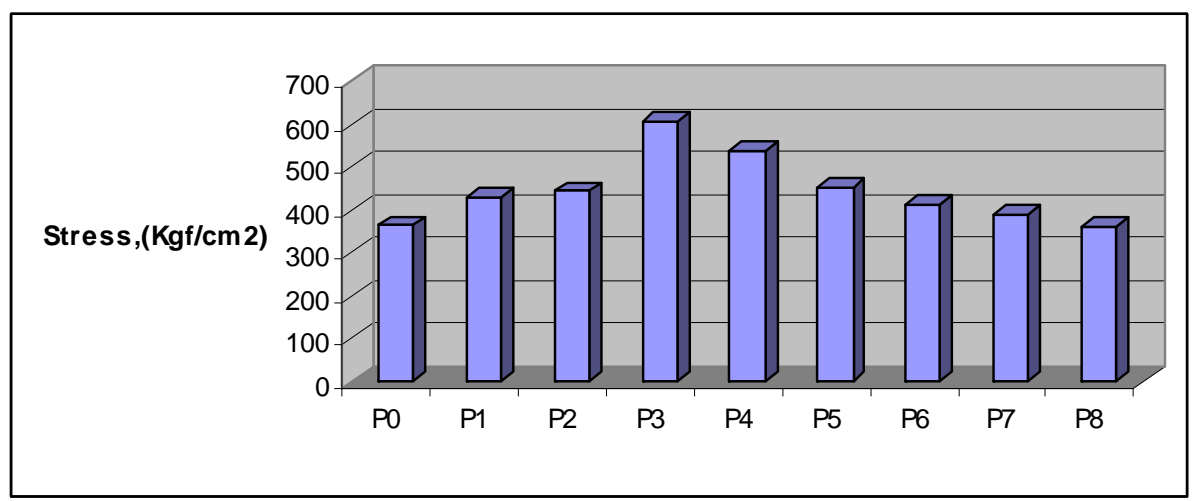

Fig. 2a Tensile Stress for neat and modified epoxies.

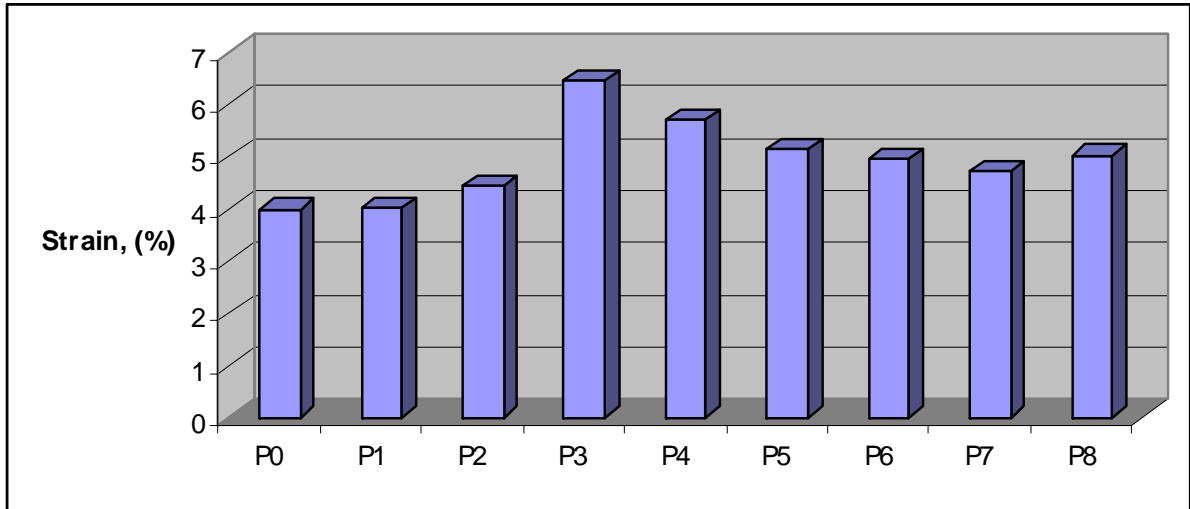

Fig. 2b Tensile Strain for neat and modified epoxies.

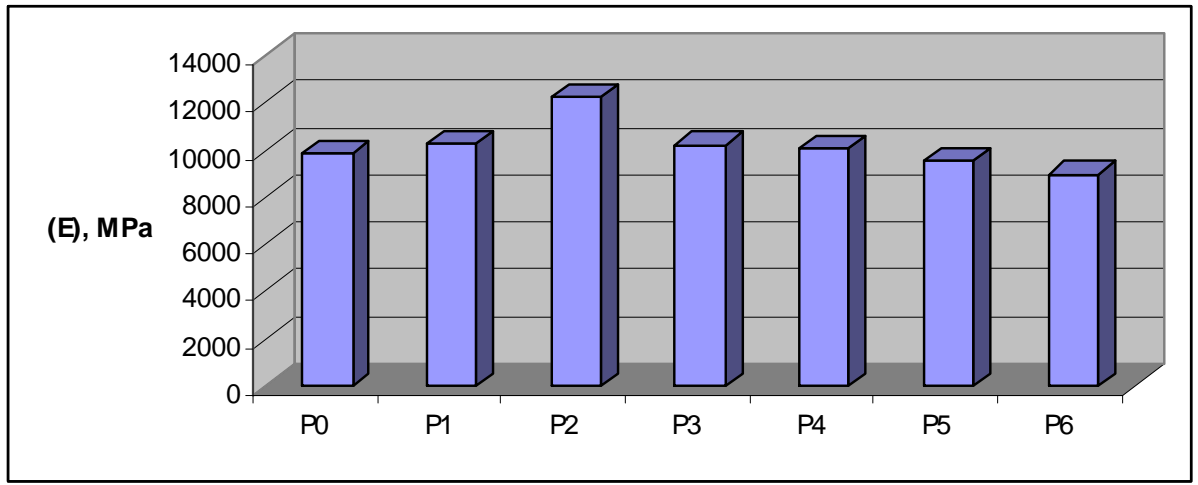

Fig. 2c Young's Modulus for neat and modified epoxies. 


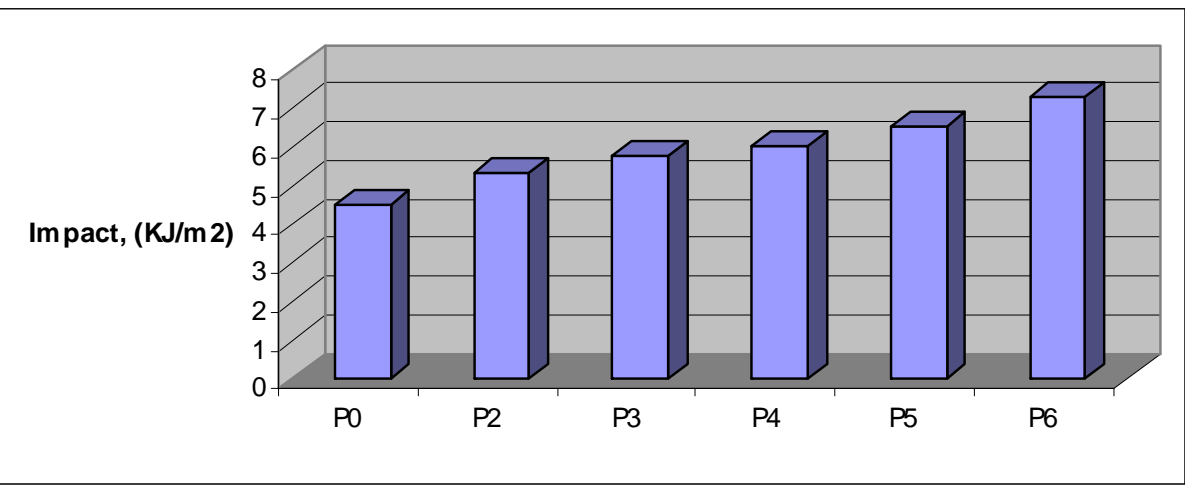

Fig. 3 Impact resistance for neat and modified epoxy resin.

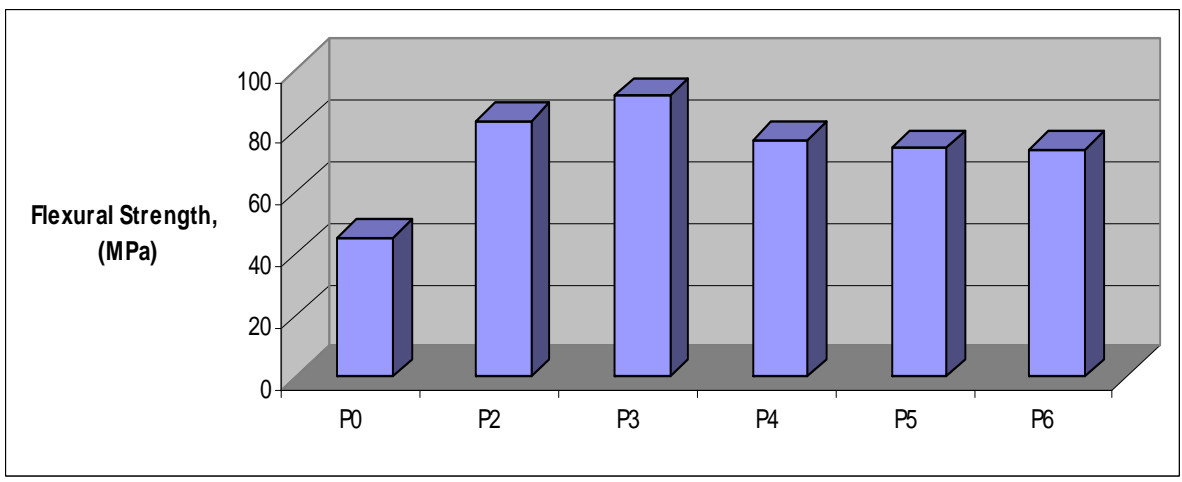

Fig. 4 Flexural strength for neat and modified epoxy resin.

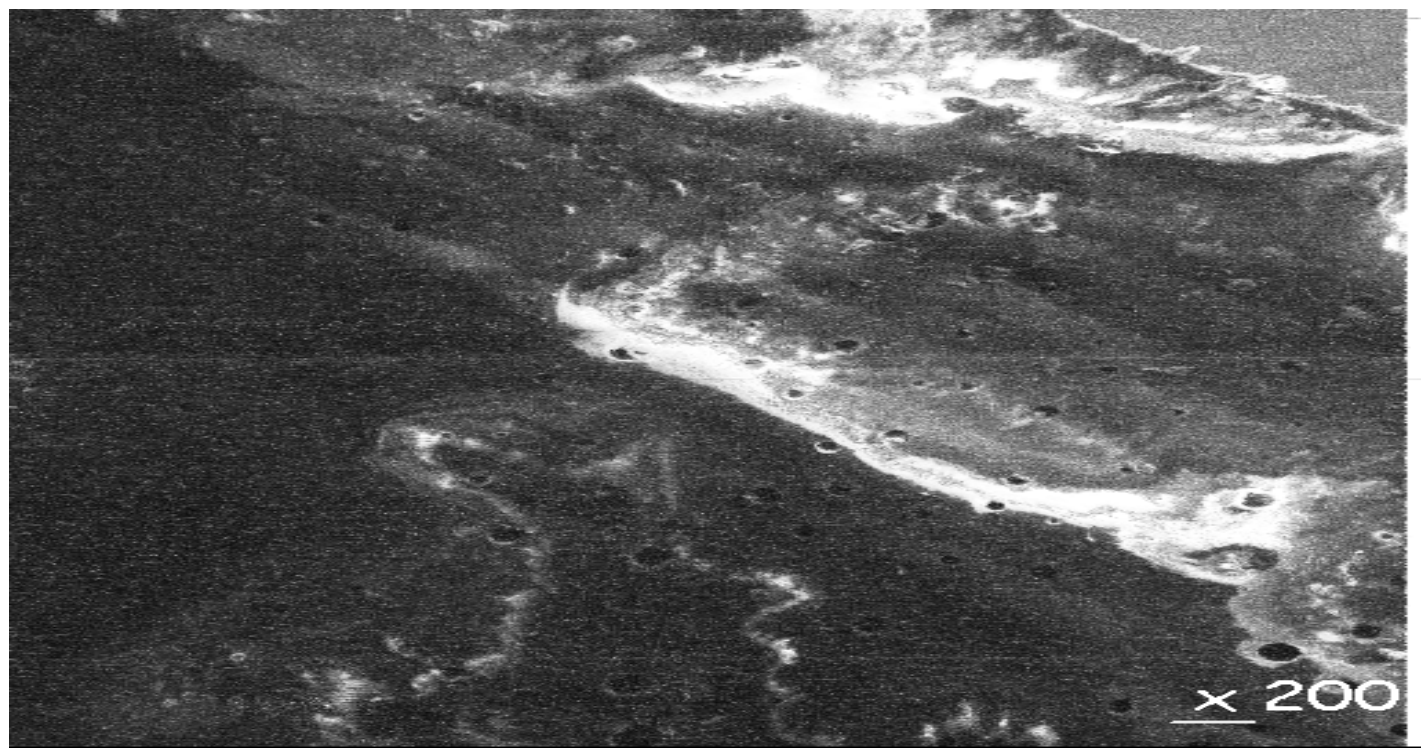

Fig. 5a SEM micrograph of 10 phr HTPB blends showing stress-whitened zone. 


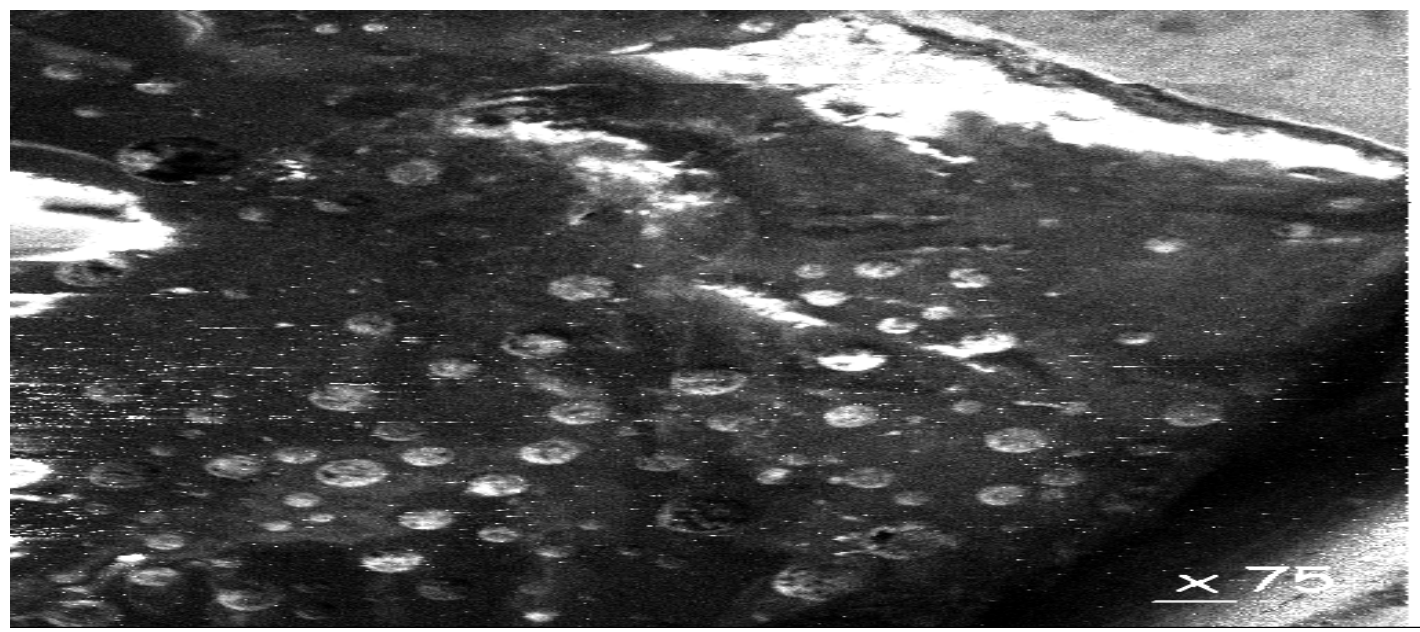

Fig. 5b SEM micrograph for neat epoxy resin.

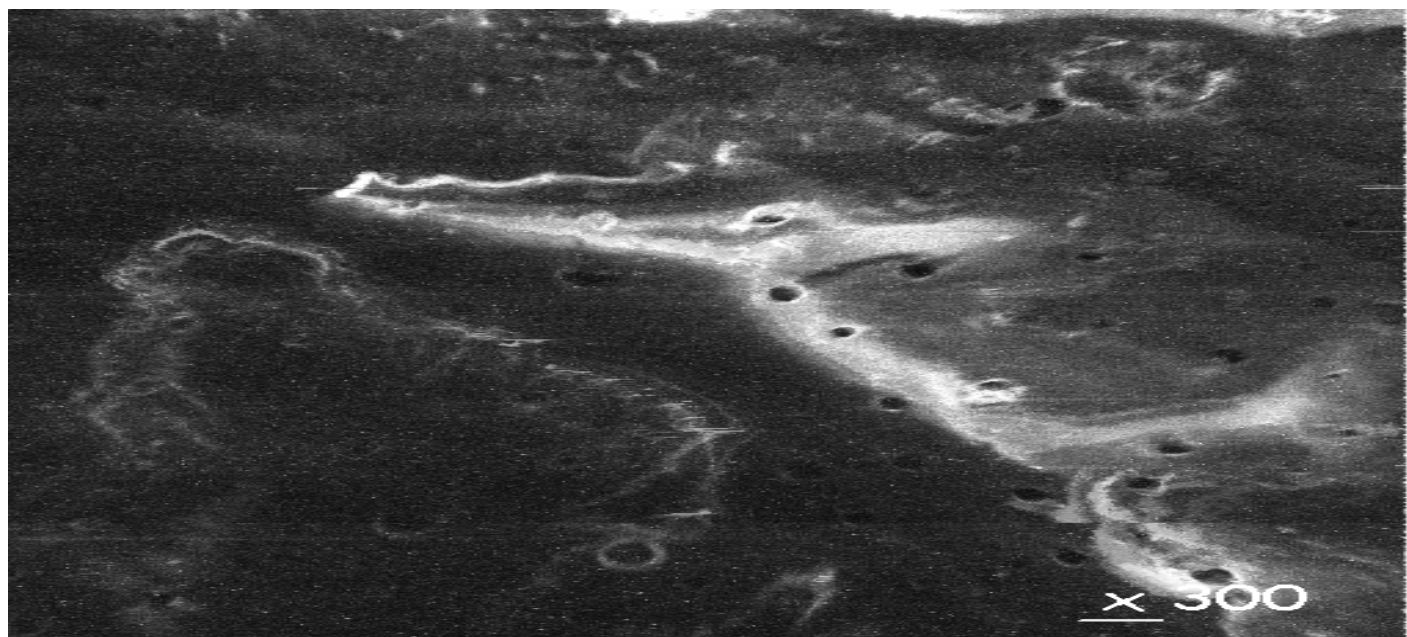

Fig. 5c SEM micrograph for 2.5- phr rubber-modified epoxies.

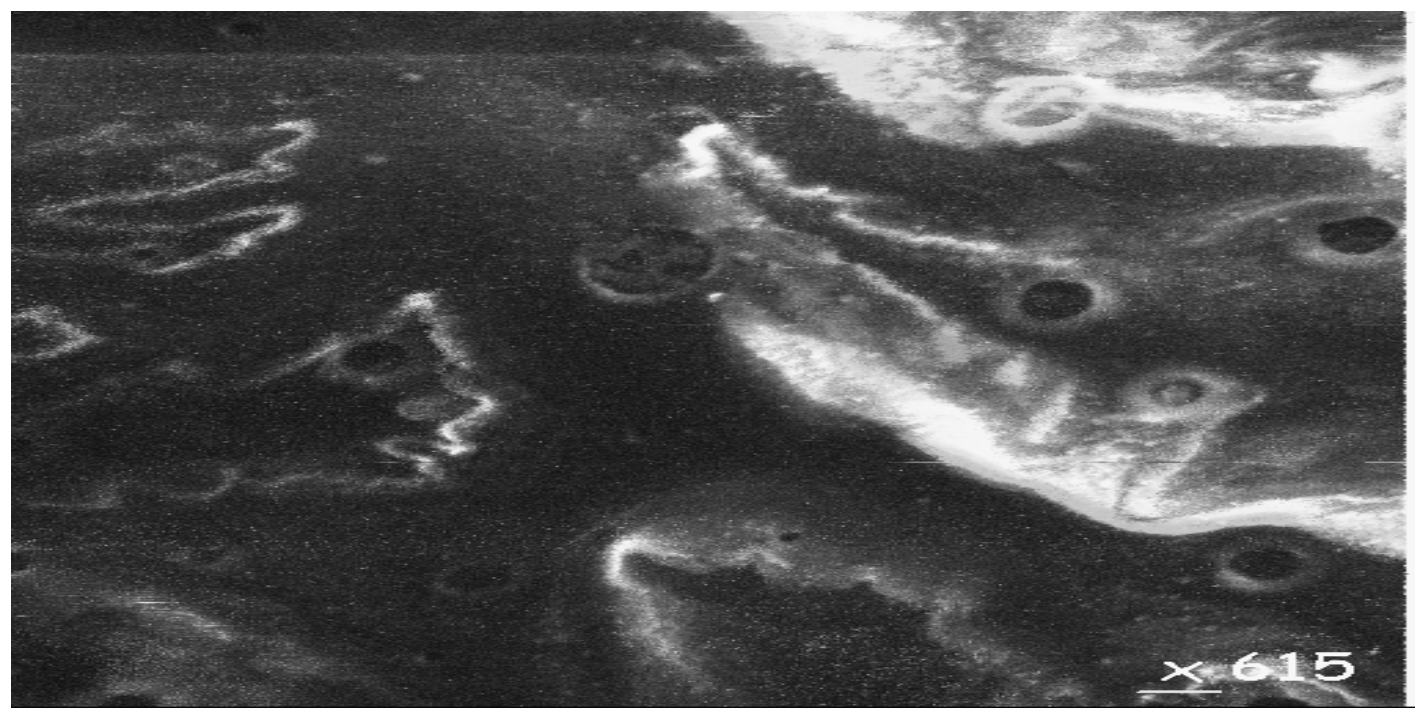

Fig. 5d SEM micrograph for 15-phr rubber-modified epoxies. 